\title{
Theta Activity in the Regio Inferior of the Temporal Hippocampus by Odor Stimulation in Anesthetized Pigs
}

\author{
Toshiyuki Saito ${ }^{1,2 *}$, Sei-Etsu Fujiwara ${ }^{2,3}$, Takashi Yamaguchi ${ }^{4}$ \\ ${ }^{1}$ Faculty of Life Sciences, Kyoto Sangyo University, Kyoto, Japan \\ ${ }^{2}$ National Institute of Agrobiological Sciences, Tsukuba, Japan \\ ${ }^{3}$ School of Medicine, St. Marianna University, Kawasaki, Japan \\ ${ }^{4}$ Graduate School of Science and Engineering, Yamagata University, Yonezawa, Japan \\ Email: *saito3ys@cc.kyoto-su.ac.jp
}

How to cite this paper: Saito, T., Fujiwara, S.-E. and Yamaguchi, T. (2017) Theta Activity in the Regio Inferior of the Temporal Hippocampus by Odor Stimulation in Anesthetized Pigs. Open Journal of Animal Sciences, 7, 365-375.

https://doi.org/10.4236/ojas.2017.74028

Received: June 24, 2017

Accepted: September 1, 2017

Published: September 4, 2017

Copyright $\odot 2017$ by authors and Scientific Research Publishing Inc. This work is licensed under the Creative Commons Attribution International License (CC BY 4.0).

http://creativecommons.org/licenses/by/4.0/

\section{Open Access}

\begin{abstract}
We examined theta activity in the temporal hippocampus of urethane-chloralose-anesthetized pigs by stimulation with two chemical odors, beta-phenyl ethyl alcohol (PEA; rose-like odor) and n-amyl acetate (banana-like odor). Neural activity was recorded in the neural cell layer nearby fimbria of the temporal hippocampus in three of six animals. Odor stimulation with PEA at a low concentration $\left(10^{-4} \mathrm{w} / \mathrm{w} ; 100 \mathrm{ppm}\right)$ significantly increased power of the low-frequency theta band (type-2; 4 - $6 \mathrm{~Hz}$ ) for the middle $10 \mathrm{~s}(\mathrm{w}(3,6,2.5 \%)>2.56)$. The PEA odor at a higher concentration $\left(10^{-3}\right.$ $\mathrm{w} / \mathrm{w} ; 1000 \mathrm{ppm}$ ), however, showed a tendency for gradual increase in the low-frequency theta but the response was insignificant compared with the control. On the other hand, odor stimulation with $n$-amyl acetate $\left(10^{-4} \mathrm{w} / \mathrm{w}\right.$; $100 \mathrm{ppm}$ ) caused no apparent increase or a tendency for decrease in power of the low-frequency theta. Thus, the type- 2 theta response in the temporal hippocampus to the PEA odor contrasted strikingly with that to the n-amylacetate in the urethane-chloralose-anesthetized pigs. The response of the type- 2 theta rhythm in the temporal hippocampus may underlie the difference in emotional sensation and cognition of PEA from n-amyl acetate in the pig.
\end{abstract}

\section{Keywords}

Fast Fourier Transform, Rhythmic Oscillations, Sus scrofa domesticus

\section{Introduction}

In the hippocampus, CA1, CA3 and the dentate gyrus can be regarded as sensory 
regions for olfactory stimulation [1] [2] [3] [4] [5]. Septal and temporal pole of the hippocampus may both receive inputs from the olfactory bulb [3] [6]. But only the temporal pole of the hippocampus can obtain olfactory input through the amygdala [7] [8]. A paper [9] further supports this view, which has described a ventral-predominant activation in the mouse hippocampus by odor stimulation.

Theta is one of the slow wave activity patterns that are recorded in the hippocampus. Hippocampal theta rhythm consists of high (type-1; $6-12 \mathrm{~Hz}$ ) and low (type-2; $4-6 \mathrm{~Hz}$ ) frequency components. In freely moving rats, the type-1 (anesthesia-sensitive) theta rhythm is elicited during head movements or locomotion [10] [11] and while sniffing as a sensorimotor process in odor discrimination [12]. In contrast, the type-2 (atropine-sensitive) theta activity is observed in immobile conscious rats, as well as in urethane-anesthetized rats [13]. Thus, role of the hippocampal theta has been investigated in the rat. But, few studies have been performed in pigs, on the relation between the hippocampal theta activity and olfaction.

In this study, we examined if odor stimulation may activate theta rhythms of the temporal hippocampus in domestic pigs (Sus scrofa domesticus) under urethane-chloralose anesthesia.

We recorded neural activity in the neural cell layer of the regio inferior, instead of that in the dentate gyrus. The former could technically be identified by a dorsal approach more readily than the latter.

\section{Materials and Methods}

\subsection{Animals}

Six male Landrace pigs (S. scrofa domesticus) weighing between 25 and $40 \mathrm{~kg}$ (at 8 - 12 weeks of age) were used. All animals received humane care as described in Care and Use of Experimental Animals of the National Institute of Agrobiological Sciences and the National Institutes of Health Guide for the Care and Use of Laboratory Animals. Each pig was housed in a cage $(1.2 \mathrm{~m} \times 0.8 \mathrm{~m})$ in a room at $23^{\circ} \mathrm{C}, 60 \%$ humidity, light 6:00 - 18:00, dark 18:00 - 6:00 for 3 or 4 days before use. All surgical interventions and experiments were performed at Zootron, National Institute of Livestock and Grassland Sciences, Tsukuba.

\subsection{Anesthesia and Surgery}

Pigs were fasted overnight but were allowed ad libitum access to water before they were used. Just before the surgery, each pig received an intramuscular injection of xylazine (2 mg/kg; Ceractal, Bayer Pharmaceuticals, Osaka, Japan) with midazolam $(0.5 \mathrm{mg} / \mathrm{kg}$; Dormicum, Astellas Pharmaceuticals, Tokyo, Japan). Deep anesthesia was then achieved through inhalation of $2 \%$ to $3 \%$ halothane (Fluothane, Takeda Pharmaceuticals, Osaka, Japan) and $0.5 \mathrm{~L} / \mathrm{min}$ to 1.0 $\mathrm{L} / \mathrm{min}$ nitrous oxide, and maintained with $1 \%$ to $2 \%$ and 0 to $0.5 \mathrm{~L} / \mathrm{min}$ nitrous oxide. No atropine was injected. 


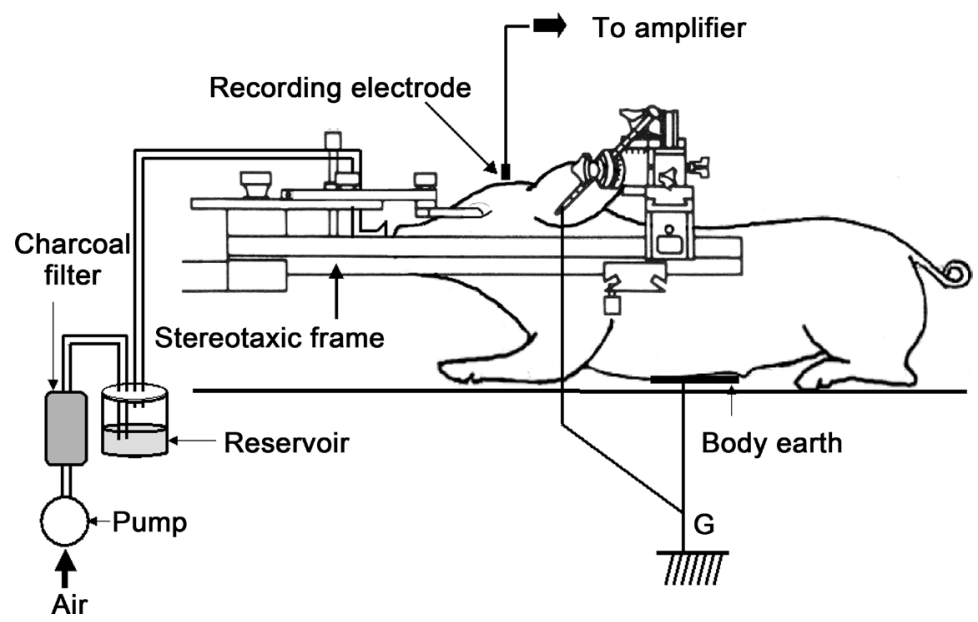

Figure 1. Recording neural activity by odor stimulation of the hippocampus in urethanechloralose-anesthetized pigs.

The head of the anesthetized pig was secured in a stereotaxic frame and the standard planes were set as described previously (Figure 1) [14]. The sagittal and coronal sutures of the skull were exposed through a midline incision and the periosteum was retracted by a dorsal approach. Bregma was noted and set as the point of origin for coordinates. The coordinates for the recording electrodes (AP-2, L13.5 in mm) were marked on the left side, and a hole was manually drilled completely through the skull at the marked location, with care taken not to penetrate the dura matter. Bone wax was applied to the skull to prevent it from drying out and bleeding. The surface of the skull was covered with gauze dipped in saline solution, until the recording electrodes were inserted under anesthesia.

We modified the method for general anesthesia in pigs with a mixture of urethane and alpha-chloralose; this technique has been reported in pigs [15]. The mixture of urethane $(500 \mathrm{mg} / \mathrm{kg})$ and alpha-chloralose $(60 \mathrm{mg} / \mathrm{kg})$ was dripped into the right external jugular vein via cannula. Fifteen to twenty minutes after the start of the drip injection, the halothane concentration in the inhalation gas was decreased stepwise by $0.5 \%$ each $10 \mathrm{~min}$. The first drip injection of urethane and alpha-chloralose was given over a 20 - to 40 -min period. If necessary, a half dose of urethane and alpha-chloralose was further administered to maintain stable anesthesia. A surgical level of anesthesia (absence of eyelid reflex, and of heart rate response to painful stimuli) was made sure before inserting recording electrodes. No halothane was inhaled when the electrodes were inserted. Rectal temperature was continuously monitored and kept at $38.7^{\circ} \mathrm{C} \pm 0.4^{\circ} \mathrm{C}$. Heart rate ranged from 118 to 140 beats per min. Respiration rate ranged from 24 to 32 breaths per min. Spontaneous breathing was maintained during the experiment.

\subsection{Measurement of Neural Activity in the Temporal Hippocampus}

After a small incision had been made on the surface of the dura matter, a comb-like electrode, which consisted of four tungsten electrodes (5755, AC im- 
pedance $5 \mathrm{Mohm}$, A-M Systems, Carlsborg, WA, USA) were inserted into the left temporal hippocampus. Neural activity was continuously displayed on an oscilloscope and audibly outputted through a speaker. An electrode was chosen in which active neuronal firing was detected at the coordinates of (AP-2, H4043, L13.5 in $\mathrm{mm}$ ). The electrode was fixed in this location. Thereafter, neural activity was recorded monopolarly (Figure 1), before (30 s), during (30 s), and after (30 s) odor stimulation in each session (Figure 2). A reference electrode was connected to the left ear-bar of the stereotaxic instrument, which was grounded with a body earth. The neural activity was then sampled and digitized at a rate of $20 \mathrm{kHz}$ after magnification (10-fold) with a conventional amplifier (AB610J, Nihon Koden, Tokyo, Japan; low-cut filter of $0.08 \mathrm{~Hz}$ ), and were stored in a computer for subsequent off-line analysis.

\subsection{Odor Stimulation}

A hand-made device was used for odor stimulation. The device consisted of an air pump, charcoal filters, Teflon reservoirs, tubes and funnels, and was set as shown in Figure 1 just before the measurement started.

Olfactory stimuli included two odorants. The first odorant was n-amyl acetate (banana-like odor), which has been called "trigeminal odorant" to elicit trigeminal responses as well as olfactory one at higher concentrations than used here by orthonasally presentation [16]. The second was beta-phenyl ethyl alcohol (rose-like odor, PEA), called "pure" odorant, which do not stimulate the trigeminal nerve.

Twenty milliliters of PEA $\left(10^{-4} \mathrm{w} / \mathrm{w}\right.$ or $10^{-3} \mathrm{w} / \mathrm{w}$; Daiichi Pharmaceutical Industry, Tokyo, Japan), n-amyl acetate $\left(10^{-4} \mathrm{w} / \mathrm{w}\right.$ or $10^{-3} \mathrm{w} / \mathrm{w}$; Wako Pharmaceuticals, Osaka, Japan) or glycerin (Daiichi Pharmaceutical Industry, Tokyo, Japan) as a control was put into each Teflon reservoir $(100 \mathrm{~mL})$. Room air (about $23^{\circ} \mathrm{C}$ ) was sent into the charcoal filter with aid of the air pump $(4 \mathrm{~L} / \mathrm{min})$. The deodorized air was then led to each reservoir through each Teflon tube. Odorized air with PEA, n-amyl acetate or the control (glycerin) then blew

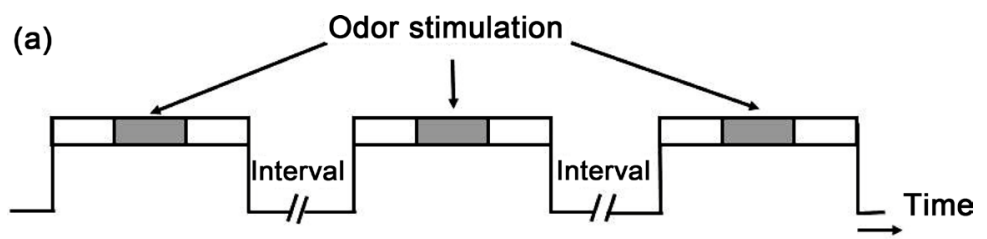

(b)

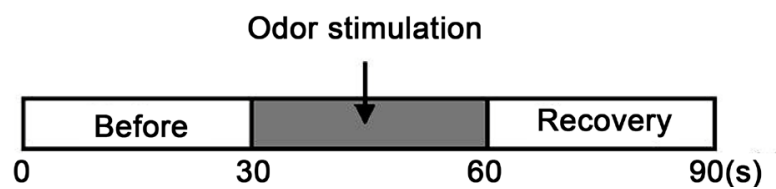

Figure 2. Schedule for odor stimulation and measurement of hippocampal neural activity. (a) Odor stimuli were provided repetitively at intervals (3 min or longer). (b) In each session, neural activity was measured for $90 \mathrm{~s}$ : before (30 s), during (30 s), and after (30 s) odor stimulation of the anesthetized pigs. 
through each tube and out of each Teflon funnel (33ø outer diameter) placed about $3 \mathrm{~cm}$ in front of the pig's nose. The dead volume in the reservoir and tube to the funnel was less than $0.15 \mathrm{~L}$.

The odor was delivered for the middle $30 \mathrm{~s}$ by turning on the air pump in each recording period of $90 \mathrm{~s}$ (Figure 2). The odor stimulation was randomly performed among control, low concentration of the odorants $\left(10^{-4} \mathrm{w} / \mathrm{w} ; 100 \mathrm{ppm}\right)$ and high concentration of the odorants $\left(10^{-3} \mathrm{w} / \mathrm{w} ; 1000 \mathrm{ppm}\right)$. Inter-recording periods were set to ensure that the pre-stimulatory neural activity recovered to the resting level. Odor delivery onset was not synchronized with respiration; the delay in onset of odor delivery was calculated from the respiratory rate and was estimated to be a maximum of $2.5 \mathrm{~s}$. After odor stimulation, the device was removed. The funnels and tubes were rinsed in ethyl alcohol (70\%), and then dried and stored for next use. The room air was ventilated to clear the odors or the control with aid of the built-in ventilator (ACP-7, Yamaha-motor, Hamamatsu, Japan; airflow rate: about $35,000 \mathrm{~L} / \mathrm{min}$ ).

\subsection{Lesions at Recording Sites}

After each experiment, a negative electrical current ( $300 \mu \mathrm{A}, 20 \mathrm{~s})$ was applied to the recording electrode under general anesthesia with halothane inhalation. The head was perfused through cannulae into bilateral internal carotid arteries with a saline solution containing heparin, followed by a $10 \%$ phosphate-buffered formalin solution ( $\mathrm{pH}$ 7.4) [14]. The brain was then removed from the skull and immersed in the $10 \%$ formalin solution ( $\mathrm{pH}$ 7.4). After the brain had been stored in a $30 \%$ sucrose solution for several days, serial coronal sections of $150 \mu \mathrm{m}$ were prepared via a freezing microtome stage and Nissl-stained [14]. The location of the electrically induced lesions was then identified on the mounted sections.

\subsection{Data Analysis}

The data were re-sampled at a rate of $200 \mathrm{~Hz}$. Power spectra for high-frequency theta (type-1; $6-12 \mathrm{~Hz}$ ) and low-frequency theta (type-2; 4 - $6 \mathrm{~Hz}$ ) were obtained every $10 \mathrm{~s}$ by fast Fourier Transform analysis by using a custom-made software program (Labview for windows, v. 7.0, National Instruments Japan, Tokyo, Japan). The total power of each frequency band was obtained with a computer-based digitizer. The value of power of the type- 1 and -2 theta for the first $10 \mathrm{~s}$ was regarded as 1 in each test session, respectively. Subsequently, value of the theta power following each $10 \mathrm{~s}$ was divided by that in the first $10 \mathrm{~s}$ and was expressed as a ratio (relative theta power).

\subsection{Statistics}

Statistical significance was examined by Williams's test for multiple comparisons [17] of relative theta power.

\subsection{Nomenclature}

The hippocampus proper of the pig is divided into two major subfields, a regio 
inferior and a regio superior [18] [19]. The former is adjacent to the dentate area and corresponds mostly to the CA3 region. The latter is adjacent to the subiculum and corresponds to the CA1 region [3] [18] [19] [20].

\section{Results}

\subsection{Recordings Sites}

Recording sites were identified from electrically induced lesions made at the tips of the recording electrodes after each experiment. The sites were verified as being located in the cell layer nearby fimbria of the temporal hippocampus in three of six pigs (1-3, Figure 3 ). In one animal, the lesion was located more laterally, in the neural cell layer near the regio superior. In the remaining two animal, the lesion was outside the hippocampus. The results mentioned below were based on the data obtained from the former three animals (recording sites $1-3$ ).

\subsection{Theta Activity in Response to Odor Stimulation}

Figure 4(a) gives examples (animal 1) of neural activity band-pass-filtered with $4-80 \mathrm{~Hz}, 6-12 \mathrm{~Hz}$ (type-1 theta) and $4-6 \mathrm{~Hz}$ (type-2 theta) during the delivery of odorized air containing glycerin or PEA. Figure 4 (b) shows the power spectra of the theta bands calculated from the corresponding recordings in Figure 4(a). In the control (Figure 4(a) and Figure 4(b), left column), there was rhythmic activities in which a small peak was observed at $4.3 \mathrm{~Hz}$ in the power spectrum; power of the type- 1 theta activity was about one-tenth that of the type- 2 theta.

During delivery of odorized air with PEA $\left(10^{-4} \mathrm{w} / \mathrm{w} ; 100 \mathrm{ppm}\right)$, analysis of the type-2 theta activity (Figure 4(a); bottom of middle column) clearly showed the large, sharp peak at $4.3 \mathrm{~Hz}$ in the power spectrum for the middle of $10 \mathrm{~s}$ (40 - 50 s) (Figure 4(b); bottom of middle column). On the other hand, analysis of the type-1 theta activity showed several peaks in the power spectrum in one pig during stimulation with PEA $\left(10^{-4} \mathrm{w} / \mathrm{w}\right)$ (Figure 4 (b), upper panel of middle column). But the remaining two pigs showed no visible changes in the power

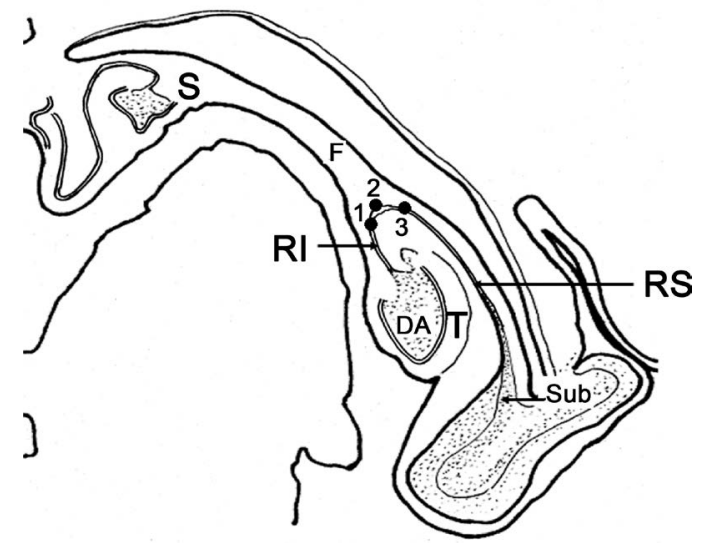

Figure 3. Illustration of electrical lesions found in the temporal hippocampus of the three pigs. One black point represents each pig's lesion. DA, dentate area; F, fimbria; RI, regio inferior; RS, regio superior; S, septal pole; Sub, subiculum; T, temporal pole. 
(a)

\section{Control}

(40-50s)

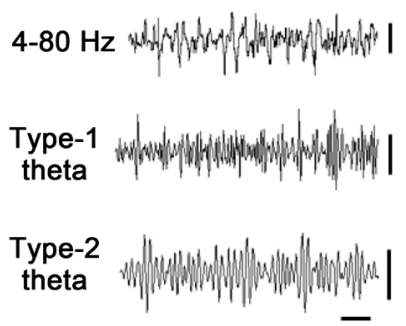

(b)

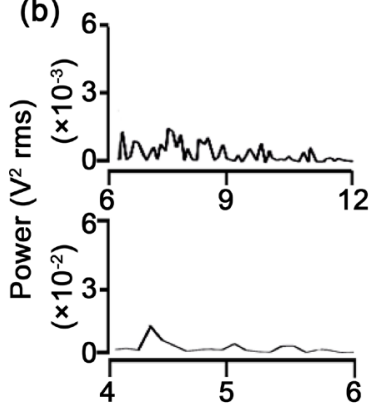

PEA $\left(10^{-4} w / w\right)$

(40-50s)
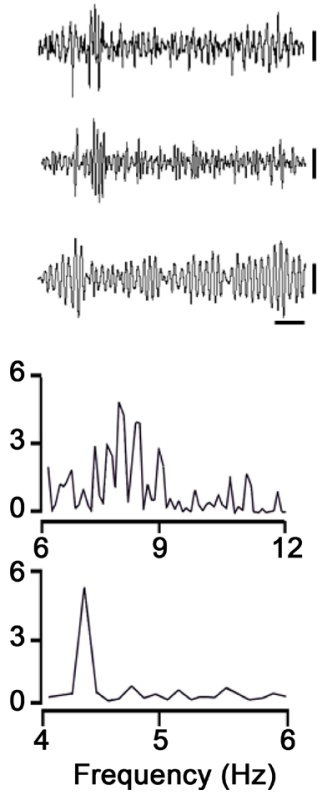

PEA $\left(10^{-3} w / w\right)$

(40-50s)
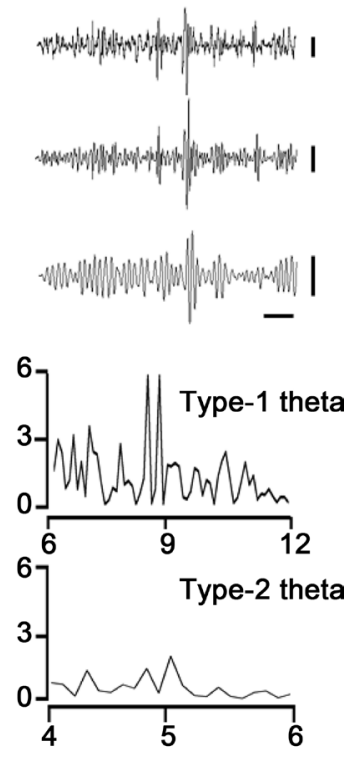

Figure 4. Examples of (a) changes in neural activity recorded for $10 \mathrm{~s}(40-50 \mathrm{~s})$ in the temporal hippocampus and (b) power spectra, during olfactory stimulation with control or PEA $\left(10^{-4} \mathrm{w} / \mathrm{w}\right.$ or $\left.10^{-3} \mathrm{w} / \mathrm{w}\right)$. In (a), neural activities bandpass-filtered between 4 and $80 \mathrm{~Hz}$ (upper panel), between 6 and $12 \mathrm{~Hz}$ (type-1 theta; middle) and between 4 and $6 \mathrm{~Hz}$ (type-2 theta; bottom) are shown. In (b), power spectra for the type-1 theta (top) and for the type-2 theta (bottom) were calculated from each recording in (A). Horizontal and vertical bars show $1 \mathrm{~s}$ and $1 \mathrm{mV}$, respectively.

spectra of the type-1 theta (data not shown).

During delivery of odorized air with higher concentration $\left(10^{-3} \mathrm{w} / \mathrm{w} ; 1000\right.$ ppm) of PEA, the type-2 theta showed no visible large peak in the power spectrum for the middle $10 \mathrm{~s}$ (40 - $50 \mathrm{~s}$ ) (Figure 4(b); bottom of right column). The type-1 theta activity showed a sign for momentary increase in power for the middle $10 \mathrm{~s}(40-50 \mathrm{~s})$. There were several peaks in the power spectrum ranging from 8 to $9 \mathrm{~Hz}$ (Figure 4(b), upper panel of right column).

Figure 5 shows the mean temporal changes in relative power of the theta activities recorded in the regio inferior nearby fimbria (animals $1-3$ ) before, during, and after the delivery of control (a) or of odorized air with PEA (b and c). The relative power of the type- 2 theta activity (right column b) was significantly elevated to $1.4 \pm 0.14$ (all values are means $\pm S D ; n=3$ ) for the middle $10 \mathrm{~s}$ (40 $50 \mathrm{~s})$ of PEA $\left(10^{-4} \mathrm{w} / \mathrm{w}\right)$ odor delivery $(\mathrm{w}(3,6,2.5 \%)>2.56)$, when compared with that in the control $(0.85 \pm 0.06 ; \mathrm{n}=3)$ (right column a) and with that in the PEA $\left(10^{-3} \mathrm{w} / \mathrm{w}\right)$ exposure $(0.91 \pm 0.22 ; \mathrm{n}=3$ ) (right column $\mathrm{c}$ ) over the same time. In contrast, the relative power of the type-1 theta activity was $1.09 \pm 0.04$ $(n=3)$ for the corresponding period of the same stimulation (Figure 5, left column $b$ and $c$ ). This value was not significantly greater than in the control $(0.88 \pm 0.13 ; \mathrm{n}=3)\left(\right.$ left column a) and in the PEA $\left(10^{-3} \mathrm{w} / \mathrm{w}\right)(1.10 \pm 0.21 ; \mathrm{n}=$ 3) (left column c). Thus, type- 2 theta activity was enhanced separately from 
Type-1 theta

(a)

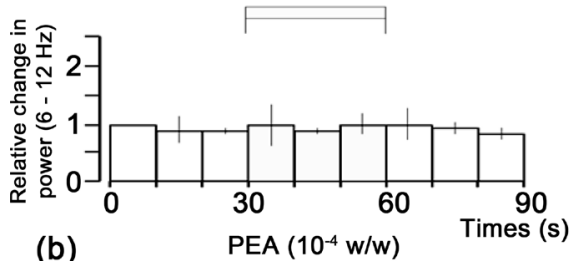

(b)

PEA $\left(10^{-4} \mathrm{w} / \mathrm{w}\right)$

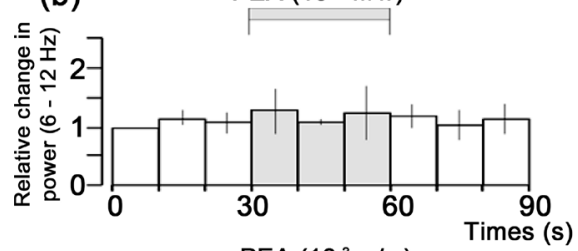

(c)

$\operatorname{PEA}\left(10^{-3} \mathrm{w} / \mathrm{w}\right)$

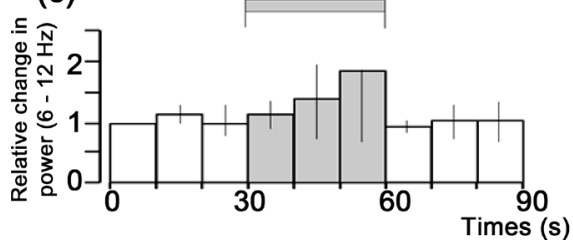

(a)

Type-2 theta

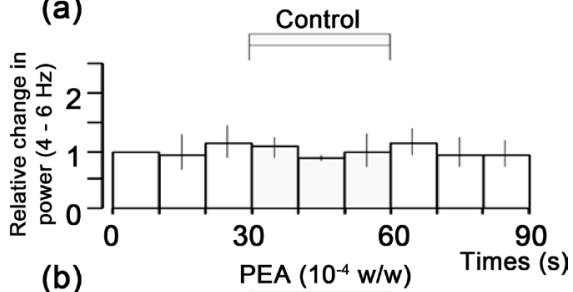

(b)

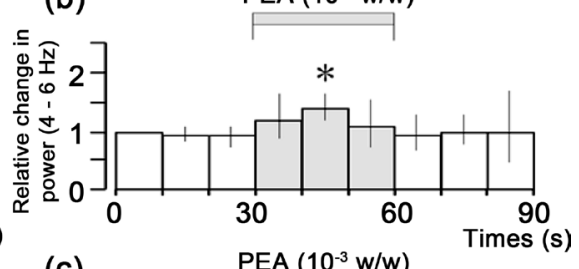

(c)

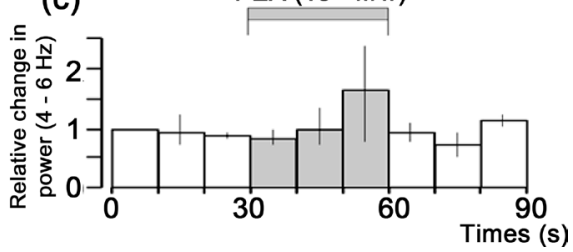

Figure 5. Change in relative power of type-1 theta $(6-12 \mathrm{~Hz}$; left column) and type-2 theta ( $4-6 \mathrm{~Hz}$; right column) activities before, during, and after odor stimulation with control (a), or PEA (b), $10^{-4} \mathrm{w} / \mathrm{w}$; (c) $\left.10^{-3} \mathrm{w} / \mathrm{w}\right)$. Data are expressed in means \pm SD. Asterisk shows statistically difference $(\mathrm{w}(3,6,2.5 \%)>2.56)$.

type-1 when PEA odor at a low concentration $\left(10^{-4} \mathrm{w} / \mathrm{w}\right)$ was delivered.

Stimulation with PEA at a higher concentration $\left(10^{-3} \mathrm{w} / \mathrm{w}\right)$ produced a tendency for enhancements of type- 1 and type- 2 theta power, especially in the late phase, i.e. the third $10 \mathrm{~s}(50-60 \mathrm{~s})$. But these increases in power were not significant in either the type-1 $(1.19 \pm 0.20 ; n=3)$ or type-2 $(1.14 \pm 0.22 ; n=3)$ theta (left and right columns c) in comparison with the control (type 1, $1.05 \pm 0.20 ; \mathrm{n}$ $=3$; type $2,1.14 \pm 0.24 ; \mathrm{n}=3$ ) (left and right columns a) with the PEA $\left(10^{-4} \mathrm{w} / \mathrm{w}\right.$ ) (type $1,1.10 \pm 0.07 ; \mathrm{n}=3$; type $2,1.20 \pm 0.46 ; \mathrm{n}=3$ ) for the corresponding period of the stimulation.

In contrast, odor stimulation with $\mathrm{n}$-amyl acetate $\left(10^{-4} \mathrm{w} / \mathrm{w} ; 100 \mathrm{ppm}\right)$ caused no apparent increase or a tendency for decrease in power of the low-frequency theta recorded in the hippocampus (data not shown).

\section{Discussion}

In this study, we newly demonstrated in the anesthetized pigs that type- 2 theta activity in the regio inferior of the temporal hippocampus was separately enhanced from type-1 theta activity by odor stimulation with PEA.

\section{Theta Activity in Response to Odor Stimulation with PEA}

\section{Low-Frequency (type-2) Theta}

The type-2 theta-power became highest with shorter latency by odor stimulation with PEA at the low concentration $\left(10^{-4} \mathrm{w} / \mathrm{w} ; 100 \mathrm{ppm}\right)$, compared with that at the higher concentration $\left(10^{-3} \mathrm{w} / \mathrm{w} ; 1000 \mathrm{ppm}\right)$ (Figure 5 right column $\mathrm{b}$ and $\mathrm{c}$ ). 
Although neural mechanisms for activation of the type-2 theta remain unclear in this study, neurons originating in the RPO and in the medial-diagonal band of Broca [13] [21] [22] may possibly be activated by exposure of PEA odor. Longer latency for increasing relative theta-2 power activity at the higher PEA concentration $\left(10^{-3} \mathrm{w} / \mathrm{w}\right)$ may be caused by more activation of inhibitory mechanisms than excitatory in the hippocampus immediately after exposure of the PEA odor. However, in the same animal as used in this experiment, we have observed the highest power of type- 2 theta activity in the first $10 \mathrm{~s}$ of delivery of odorized air with isoamylacetate $\left(10^{-3} \%\right.$, a very similar concentration to that of PEA used here) (Saito et al. unpublished observation). Longer or shorter latency for the type-2 theta activation might be related to odor's strength or acceptability in pig.

Another possibility is there may be spatial variations in the temporal hippocampus receiving olfactory inputs. In case of recording in the regio superior,

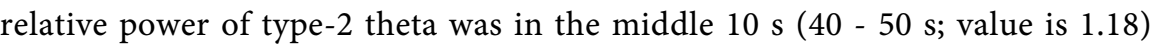
during odor stimulation with PEA $\left(10^{-4} \mathrm{w} / \mathrm{w}\right)$, and further increased to 2.88 in the last $10 \mathrm{~s}(50-60 \mathrm{~s})$. More surprisingly, relative power of type-1 theta was clearly elevated to 1.86 and 1.92 at the same location for the first and the last $10 \mathrm{~s}$ during stimulation with PEA $\left(10^{-4} \mathrm{w} / \mathrm{w}\right)$, and to 3.50 in the last $10 \mathrm{~s}(50-$ $60 \mathrm{~s}$ ) during stimulation with PEA $\left(10^{-3} \mathrm{w} / \mathrm{w}\right)$ (Saito et al., unpublished observation).

\section{High-Frequency (Type-1) Theta}

In the urethane-chloralose-anesthetized pigs, power of the type- 1 is much less (one-tenth) than that of the type-2 in the regio inferior (Figure 4(b)). During exposure to PEA $\left(10^{-4} \mathrm{w} / \mathrm{w}\right.$ and $\left.10^{-3} \mathrm{w} / \mathrm{w}\right)$, no significant increase was obtained in power of the type- 1 theta rhythm (Figure 5 left column b and c) unlike in that of type- 2 theta. Neural activity including the odor-specific theta [5-12 Hz] cells [23] may be probably suppressed under urethane-chloralose anesthesia, which produces type- 1 theta rhythm in the porcine brain. Indeed, there was no apparent sniffing- or locomotion-like movement in the anesthetized pig, even if odor stimulation with high concentration of PEA is applied to the animal. To examine the correlation between the type- 1 theta activity of the hippocampus and sniffing or locomotion, further study is required in conscious pigs, since the type-1 theta rhythm is correlated with sniffing- or locomotion-like movement in the conscious rat [10] [11] [12].

\section{Conclusion}

Power of type- 2 theta activity could be enhanced in the regio inferior of the temporal hippocampus of the urethane-chloralose-anesthetized pigs, when odor stimulation was performed with PEA. Activation of the type- 2 theta in the temporal hippocampus may underlie emotional sensation and cognition of PEA odor in the pig. However, further investigation needs to reveal roles of the theta activity in the hippocampus for cognition of PEA odor and behavioral correlates using conscious pigs. 


\section{Acknowledgements}

The authors acknowledge with gratitude Ms. H. Morikawa, Laboratory of Neurobiology, National Institute of Agrobiological Sciences, for her skillful support in the surgical procedures. We also thank the staff of the porcine management section of the National Institute of Livestock and Grassland, Tsukuba, for their skillful management and the supply of the animals.

This study was in part supported by the Research Program on Behavioral Mechanisms in Domestic Animals and Insects (2002-2006) of the National Institute of Agrobiological Sciences, Tsukuba, Japan.

\section{Conflict of Interests}

There is no conflict of interests.

\section{References}

[1] Cragg, B.G. (1960) Responses of the Hippocampus to Stimulation of the Olfactory Bulb and of Various Nerves in Five Mammals. Experimental Neurology, 2, 547-572. https://doi.org/10.1016/0014-4886(60)90031-5

[2] Wilson, R.C. and Steward, O. (1978) Polysynaptic Activation of the Dentate Gyrus of the Hippocampal Formation: An Olfactory Input via the Lateral Entorhinal Cortex. Experimental Brain Research, 33, 523-534. https://doi.org/10.1007/BF00235572

[3] Habets, A.M.M.C., Lopes Da Silva, F.H. and Mollevanger, W.J. (1980) An Olfactory Input to the Hippocampus of the Cat: Field Potential Analysis. Brain Research, 182, 47-74. https://doi.org/10.1016/0006-8993(80)90829-X

[4] Schwerdtfeger, W.K., Buhl, E.H. and Germroth, P. (1990) Disynaptic Olfactory Input to the Hippocampus Mediated by Stellate Cells in the Entorhinal Cortex. Journal of Comparative Neurology, 292, 163-177. https://doi.org/10.1002/cne.902920202

[5] Granger, R. and Lynch, G. (1991) Higher Olfactory Processes: Perceptual Learning and Memory. Current Opinions in Neurobiology, 1, 209-214. https://doi.org/10.1016/0959-4388(91)90080-Q

[6] Uva, L. and de Curtis, M. (2005) Polysynaptic Olfactory Pathway to the Ipsi- and Contralateral Entorhinal Cortex Mediated via the Hippocampus. Neuroscience, 130, 249-258. https://doi.org/10.1016/j.neuroscience.2004.08.042

[7] Van Groen, T. and Wyss, J.M. (1990) Extrinsic Projections from Area CA1 of the Rat Hippocampus: Olfactory, Cortical, Subcortical, and Bilateral Hippocampal Formation Projections. Journal of Comparative Neurology, 302, 515-528. https://doi.org/10.1002/cne.903020308

[8] Majak, K. and Pitkaenen, A. (2003) Projections from the Periamygdaloid Cortex to the Amygdaloid Complex, the Hippocampal Formation, and the Parahippocampal Region: A PHA-L Study. Hippocampus, 13, 922-942.

https://doi.org/10.1002/hipo.10134

[9] Kent, K., Hess, K., Tonegawa, S. and Small, S.A. (2007) CA3 NMDA Receptors Are Required for Experience-Dependent Shifts in Hippocampal Activity. Hippocampus, 17, 1003-1011. https://doi.org/10.1002/hipo.20332

[10] Vanderdolf, C.H. (1988) Cerebral Activity and Behavior: Control by Central Cholinergic and Serotonergic Systems. International Review of Neurobiology, 30, 255-340.

[11] Vanderdolf, C.H. (1992) Hippocampal Activity, Olfaction, and Sniffing: An Olfac- 
tory Input to the Dentate Gyrus. Brain Research, 593, 197-208.

[12] Kay, L.M. (2005) Theta Oscillations and Sensorimotor Performance. Proceedings of National Academy of Sciences of the United States of America, 102, 3863-3868. https://doi.org/10.1073/pnas.0407920102

[13] Bland, B.H. and Oddie, S.D. (2001) Theta Band Oscillation and Synchrony in the Hippocampal Formation and Associated Structures: The Case for Its Role in Sensorimotor Integration. Behavioral Brain Research, 127, 119-136.

[14] Saito, T., Bjarkam, C.R., Nakamura, M. and Nemoto, T. (1998) Determination of Stereotaxic Coordinates for the Hippocampus in the Domestic Pig. Journal of Neuroscience Methods, 80, 29-36.

[15] Tournadre, J.P., Allaouchiche, B., Malbert, C.H. and Chassard, D. (2000) Metabolic Acidosis and Respiratory Acidosis Impair Gastro-Pyloric Motility in Anesthetized Pigs. Anesthesia \& Analgesia, 90, 74-79. https://doi.org/10.1097/00000539-200001000-00018

[16] Laska, M., Distel, H. and Hudson, R. (1997) Trigeminal Perception of Odorant Quality in Congenitally Anosmic Subject. Chemical Senses, 22, 447-456. https://doi.org/10.1093/chemse/22.4.447

[17] Williams, D.A. (1972) The Comparison of Several Dose Levels with a Zero Dose Control. Biometrics, 28, 519-531. https://doi.org/10.2307/2556164

[18] Holm, I.E. and West, M.J. (1994) Hippocampus of the Domestic Pig: A Stereological Study of Subdivisional Volumes and Neuron Numbers. Hippocampus, 4, 115-126. https://doi.org/10.1002/hipo.450040112

[19] Holm, I.E. (1995) The Hippocampal Region of the Domestic Pig. Aarhus University Press, Aarhus, 9-76.

[20] Blackstad, T.W. (1956) Commissural Connections of the Hippocampal Region in the Rat, with Special Reference to Their Mode of Termination. Journal of Comparative Neurology, 105, 417-536. https://doi.org/10.1002/cne.901050305

[21] Gaztelu, J.M. and Buno, W. (1982) Septo-Hippocampal Relationships during EEG Theta Rhythm. Electroencephalography and Clinical Neurophysiology, 54, 375-387.

[22] Brazhnik, E.S. and Fox, S.E. (1997) Intracellular Recordings from Medial Septal Neurons during Hippocampal Theta Rhythm. Experimental Brain Research, 114, 442-453. https://doi.org/10.1007/PL00005653

[23] Wiebe, S.P. and Staeubli, U.A. (2001) Recognition Memory Correlates of Hippocampal Theta Cells. Journal of Neuroscience, 21, 3955-3967. 